\title{
Interstitial Laser Photocoagulation Using 980 nm Diode Laser in Benign Thyroid Nodule: A Feasibility Study
}

Jeong Hwan Moon ${ }^{1,2,3}$, Raktim Biswas ${ }^{3}$, Dong Soo You ${ }^{4}$, Phil-Sang Chung 1,2,3*

${ }^{1}$ Department of Otolaryngology-Head and Neck Surgery, College of Medicine, Dankook University, Cheonan, Republic of Korea

${ }^{2}$ Beckman Laser Institute Korea, Dankook University, Cheonan, Republic of Korea

${ }^{3}$ Laser Translational Clinical Trial Center, Dankook University Hospital, Cheonan, Republic of Korea

${ }^{4}$ Department of Radiology, Dankook University Hospital, Cheonan, Republic of Korea

\begin{abstract}
The aim of this study was to investigate the feasibility of using $980 \mathrm{~nm}$ diode laser for interstitial laser photocoagulation (ILP) before clinical application in benign thyroid nodule treatment. The bovine livers were cut into blocks to irradiate with $980 \mathrm{~nm}$ laser through the lumen of a 20-gauge spinal needle using a fiber optic guide. Laser irradiation was performed with the output power of $2 \mathrm{~W}$ and $3 \mathrm{~W}$ for 60,120 and 180 seconds respectively. The liver blocks containing lesions were dissected along the axis of the fiber optic tracts and then cut transversely into slices. The thermal effect was evaluated by measuring the dimensions of the zone of coagulation necrosis. We present a case treated with $980 \mathrm{~nm}$ diode laser for the benign large thyroid nodule. All the irradiated areas zone measured in the gross specimens were $5.5 \mathrm{~mm} \pm 1.4 \mathrm{~mm}(2 \mathrm{~W}, 60 \mathrm{~s}), 6.9 \mathrm{~mm} \pm 1.4 \mathrm{~mm}(2 \mathrm{~W}, 120 \mathrm{~s}), 7.3 \mathrm{~mm} \pm 0.5 \mathrm{~mm}(2 \mathrm{~W}$, $180 \mathrm{~s}), 8.8 \mathrm{~mm} \pm 2.2 \mathrm{~mm}(3 \mathrm{~W}, 60 \mathrm{~s}), 9.2 \mathrm{~mm} \pm 0.8 \mathrm{~mm}(3 \mathrm{~W}, 120 \mathrm{~s}), 12.5 \mathrm{~mm} \pm 4.1 \mathrm{~mm}(3 \mathrm{~W}, 180 \mathrm{~s})$ respectively. The transverse diameter was as $5.1 \mathrm{~mm} \pm 0.5 \mathrm{~mm}(2 \mathrm{~W}, 60 \mathrm{~s}), 6.1 \mathrm{~mm} \pm 0.2 \mathrm{~mm}(2 \mathrm{~W}, 120 \mathrm{~s}), 9.9 \mathrm{~mm} \pm 2.5 \mathrm{~mm}(2$ $\mathrm{W}, 180 \mathrm{~s}), 6.2 \mathrm{~mm} \pm 1.8 \mathrm{~mm}(3 \mathrm{~W}, 60 \mathrm{~s}), 7.7 \mathrm{~mm} \pm 1.2 \mathrm{~mm}(3 \mathrm{~W}, 120 \mathrm{~s}), 8.8 \mathrm{~mm} \pm 0.7 \mathrm{~mm}(3 \mathrm{~W}, 180 \mathrm{~s})$ respectively. ILP was well tolerated and there was no complication. Interstitial laser photocoagulation with $980 \mathrm{~nm}$ diode laser induces well-defined tissue ablation correlated with energy parameters in bovine liver tissue and therefore, could be an efficient therapeutic tool in benign thyroid nodular disease.
\end{abstract}

Keywords: $980 \mathrm{~nm}$; Diode laser; Thyroid nodule; Photocoagulation

\section{Introduction}

A thyroid nodule may harbor thyroid neoplasm though it is rare. The prevalence of thyroid nodule with age is increasing worldwide every year and the approximate prevalence ranges from $20 \%$ to $70 \%$ in USA $[1,2]$. Surgery is useful for the definitive therapy for symptomatic thyroid nodules and should be regarded as standard treatment [3]. However, the treatment modality for symptomatic thyroid nodules is changing nowadays. Both ethanol injection and thermal energy are already known treatment modality for inducing necrosis and subsequent nodule shrinkage. Interstitial laser photocoagulation (ILP) is an effective therapeutic option for the treatment of thyroid nodule. It generates thermal energy which induces necrosis in benign lesions with minimal damage to the surrounding tissues [4]. ILP is safe and effective and is considered as a moderately expensive intervention. It uses various methods depending upon the laser energy like photocoagulation which is applied by inserting a diffuser tip into the nodule. Dossing et al. in 2002 and Pacella et al. in 2004 introduced ultrasound (US)-guided laser photocoagulation for the treatment of benign thyroid nodules which showed some side effects like vacuolization of the tissues [5,6]. Moreover, most commonly used lasers require higher exposure time and power level to create effective thermal ablation and have some limitations for the bigger thyroid nodules. Therefore, ILP requires optimal irradiation energy and exposure time for effective tissue ablation with minimum side effects. The diode-based ILP systems operating in the range of 805 $\mathrm{nm}$ to $980 \mathrm{~nm}$ are being used recently for their ability to create larger ablation zones in a shorter period of time [7]. In our present study, we have investigated the safety and effectiveness of a 980-nm diode laserinduced interstitial laser photocoagulation (ILP) in the benign thyroid nodule treatment. The $980 \mathrm{~nm}$ wavelength diode laser is able to generate localized heating rapidly and creating ablation zones using relatively low output power [7]. Therefore, the aim of this study is to find the feasibility of using $980 \mathrm{~nm}$ ILP to reduce large thyroid nodules with relatively low irradiation time and power.

\section{Materials and Methods}

\section{Preparation of liver block}

Bovine livers were collected and cut into $3 \mathrm{~cm} \times 3 \mathrm{~cm} \times 3 \mathrm{~cm}$ blocks. The blocks were divided into twelve groups depending on laser powers, laser ablation times and dissection axis. Each experimental group contains six liver blocks.

Group 1: 2 Watts for 60, 120, 180 seconds

Group 2: 3 Watts for 60, 120, 180 seconds

\section{Delivery of laser energy}

For laser photocoagulation, a 21-gauge spinal needle was inserted into the liver block and the fiber-optic guide was inserted through the needle lumen so that the fiber tip was placed in direct contact with the tissue. Laser irradiation in the liver blocks was performed with the 980$\mathrm{nm}$ diode laser (Thy laser, WON Technology Co., Ltd., Korea) with an output power of $2 \mathrm{~W}$ (Group 1) and $3 \mathrm{~W}$ for 60,120 , and 180 seconds (Group 2) respectively.

\section{Measurement of thermal effect}

The inner and outer surface temperature at the zone of coagulation was recorded in every 10 seconds during the laser energy delivery. The

*Corresponding author: Phil-Sang Chung, Beckman Laser Institute Korea Dankook University, Cheonan, Republic of Korea, Tel: +82-41-550-3975 Fax: +82-41-556-1090; E-mail: 12030445@dankook.ac.kr

Received August 04, 2017; Accepted September 04, 2017; Published September 09, 2017

Citation: Moon JH, Biswas R, You DS, Chung P (2017) Interstitial Laser Photocoagulation Using $980 \mathrm{~nm}$ Diode Laser in Benign Thyroid Nodule: A Feasibility Study. J Clin Case Rep 7: 1017. doi: 10.4172/2165-7920.10001017

Copyright: () $2017 \mathrm{Moon} \mathrm{JH}$, et al. This is an open-access article distributed under the terms of the Creative Commons Attribution License, which permits unrestricted use, distribution, and reproduction in any medium, provided the original author and source are credited. 
inner temperature was recorded by a digital multimeter (Fluke 179, Fluke Co. USA) and the outer surface temperature was measured by infrared thermometer (Fluke 62, Fluke Co. USA).

\section{Measurement of lesion-size}

After the laser photocoagulation, the liver blocks including lesions were dissected along the axis of the fiber-optic tip and following a cut transversely into slices. Each liver block containing zone of coagulation necrosis, the vertical diameter (Dv) of the ablation region along the axis of the electrode insertion, the long-axis diameter (Dl) the ablation distance perpendicular to the electrode insertion and the short-axis diameter (Ds) of the ablation regions along were measured by calipers and the volume of the ablation zone was calculated by the following formula.

$\pi(\mathrm{Dv} \times \mathrm{Dl} \times \mathrm{Ds}) / 6(\mathrm{Dv}$ : Vertical Diameter; Dl: Long-Axis Diameter; Ds: Short-Axis Diameter)

\section{Case Report}

The study protocol was approved by the Institutional Review Board. The patient gave their written informed consent for the treatment with ILP after they were appropriately informed about the study. A 40-yearold woman had a benign palpable thyroid nodule that was evaluated clinically with US-guided fine needle aspiration biopsy. The patient had normal thyroid function, as determined by serum thyroid-stimulating hormone levels, T4. ILP was performed on an outpatient basis after the administration of local anesthesia. Under sterile conditions and with US guidance, a 21-gauge needle was positioned centrally in the thyroid nodule and the laser fiber placed in the lumen of the needle. The needle was withdrawn for about $20 \mathrm{~mm}$, leaving the end of the fiber in direct contact with the tissue. The patient was treated for 90 seconds with an output power of $3 \mathrm{~W}$. Thyroid nodule volume was assessed by USA.

\section{Statistical analysis}

Each value was shown by mean \pm standard deviation. The measured values were evaluated by two sample T-test and one-way ANOVA. Statistical significance was set at $\mathrm{p}<0.05$.

\section{Results}

\section{Thermal effect}

The outer temperature of the liver block was $16.4^{\circ} \mathrm{C} \pm 0.2^{\circ} \mathrm{C}$ before the laser ablation. The temperature remained unchanged for the first 60 seconds in $2 \mathrm{~W}$ laser ablation. An insignificant increase of $16.4^{\circ} \mathrm{C} \pm$ $0.4^{\circ} \mathrm{C}$ was found in 120 seconds whereas temperature reached $17^{\circ} \mathrm{C} \pm$ $0.6^{\circ} \mathrm{C}$ after 180 seconds which indicates there was no significant change in outer temperature in $2 \mathrm{~W}$ laser photocoagulation. On the other hand, outer temperature of the liver block increased from $16.4^{\circ} \mathrm{C} \pm 0.2^{\circ} \mathrm{C}$ to $16.8^{\circ} \mathrm{C} \pm 0.4^{\circ} \mathrm{C}$ in 60 seconds and up to $18.33^{\circ} \mathrm{C} \pm 0.6^{\circ} \mathrm{C}$ in 120 seconds. The final temperature recorded after 180 seconds was $19.5^{\circ} \mathrm{C} \pm 0.9^{\circ} \mathrm{C}$ for $3 \mathrm{~W}$ laser ablation. The line graph (Figure 1a) shows the temperature difference between $2 \mathrm{~W}$ and $3 \mathrm{~W}$ laser on the surface of the liver block.

Inner temperature, shown in Figure $1 \mathrm{~b}$ at the zone of coagulation necrosis during the laser delivery was higher compared to the outer surface. For $2 \mathrm{~W}$ laser energy, the temperature changed from $16.4^{\circ} \mathrm{C}$ $\pm 2.3^{\circ} \mathrm{C}$ to $18.0^{\circ} \mathrm{C} \pm 2.4^{\circ} \mathrm{C}$ for the first 60 seconds, from $18.0^{\circ} \mathrm{C} \pm 2.4^{\circ} \mathrm{C}$ to $20.7^{\circ} \mathrm{C} \pm 1.1^{\circ} \mathrm{C}$ for next 60 seconds (total 2 minutes) and after 180 seconds it reaches $24.2^{\circ} \mathrm{C} \pm 2.8^{\circ} \mathrm{C}$. Therefore, the change in temperature was only $7.8^{\circ} \mathrm{C}$ after 3 minutes. The increase in temperature was more in $3 \mathrm{~W}$ laser. It increased from $16.4^{\circ} \mathrm{C} \pm 2.2^{\circ} \mathrm{C}$ to $18.46^{\circ} \mathrm{C} \pm 2.5^{\circ} \mathrm{C}$ in first 60 seconds, $23.13^{\circ} \mathrm{C} \pm 3.0^{\circ} \mathrm{C}$ after 120 seconds and $27.0^{\circ} \mathrm{C} \pm 3.1^{\circ} \mathrm{C}$ (a)

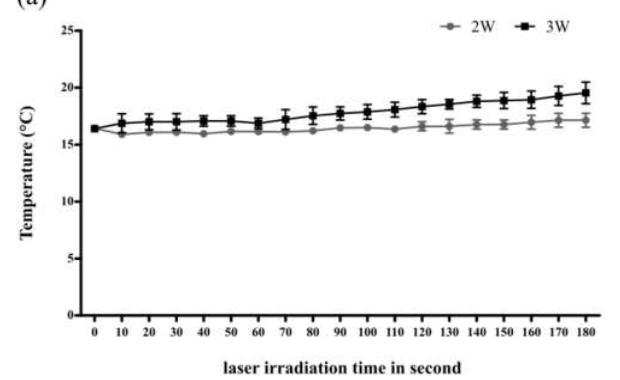

(b)

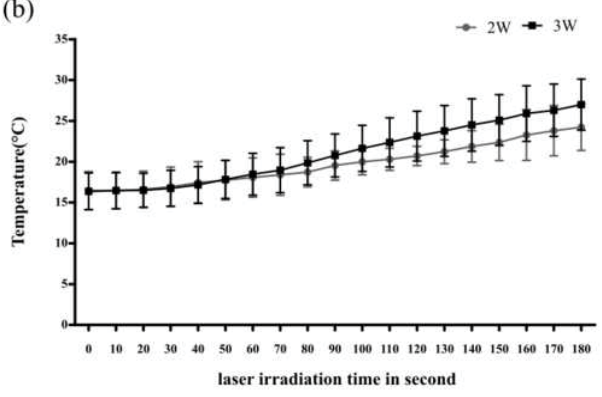

Figure 1: (a) Variation of Inner surface temperature between $2 \mathrm{~W}$ and $3 \mathrm{~W}$. (b) Variation of outer surface temperature between $2 \mathrm{~W}$ and $3 \mathrm{~W}$. (a)



$1 \mathrm{~min}$

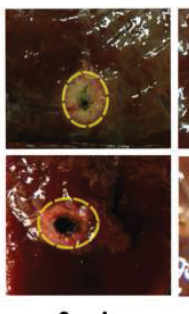

$2 \mathrm{~min}$

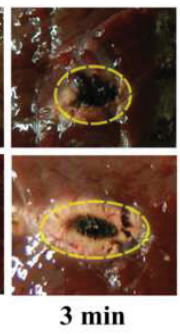

(b)

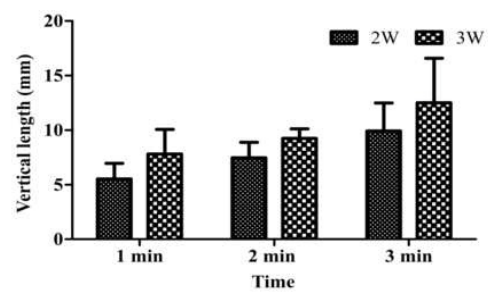

Figure 2: (a) Vertical cross-section after laser ablation. (b) Vertical length of ablation lesion for various laser settings.

after 180 seconds. So, the temperature change within 180 seconds is approximately $10.6^{\circ} \mathrm{C}$ inside the liver block.

\section{Effects of tissue ablation}

The effects of tissue ablation were measured by measuring the zone of coagulation necrosis. The longitudinal diameter of the central white zone increased with the laser energy and the laser ablation time. The longitudinal diameters were $5.5 \mathrm{~mm} \pm 1.4 \mathrm{~mm}(2 \mathrm{~W}, 60 \mathrm{~s}), 6.9 \mathrm{~mm} \pm$ $1.4 \mathrm{~mm}(2 \mathrm{~W}, 120 \mathrm{~s}), 7.3 \mathrm{~mm} \pm 0.5 \mathrm{~mm}(2 \mathrm{~W}, 180 \mathrm{~s}), 8.8 \mathrm{~mm} \pm 2.2 \mathrm{~mm}$ $(3 \mathrm{~W}, 60 \mathrm{~s}), 9.2 \mathrm{~mm} \pm 0.8 \mathrm{~mm}(3 \mathrm{~W}, 120 \mathrm{~s}), 12.5 \mathrm{~mm} \pm 4.1 \mathrm{~mm}(3 \mathrm{~W}$, $180 \mathrm{~s}$ ) respectively (Figures $2 \mathrm{a}$ and $2 \mathrm{~b}$ ). The transverse diameters also were increased with the laser energy and the laser ablation time. The transverse diameters were $5.1 \mathrm{~mm} \pm 0.5 \mathrm{~mm}(2 \mathrm{~W}, 60 \mathrm{~s}), 6.1 \mathrm{~mm} \pm 0.2$ 
(a)

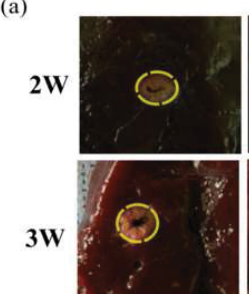

$1 \mathrm{~min}$

(b)

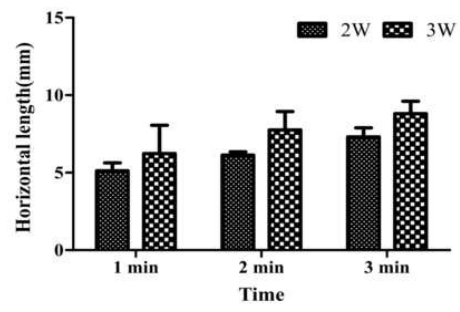

Figure 3: (a) Horizontal cross-section after laser ablation. (b) Horizontal length of ablation lesion for various laser settings.



Figure 4: Volume of the ablation lesion for various laser settings.

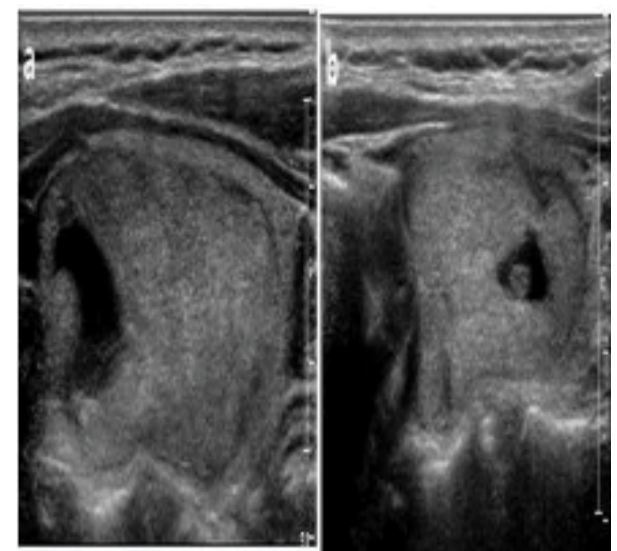

Figure 5: US images in thyroid nodule of 40-year-old woman. (a) Before ILP, longitudinal US image shows $2.4 \mathrm{~cm} \times 1.6 \mathrm{~cm} \times 4.16 \mathrm{~cm}$ isoechoic nodule with central cystic portion in left thyroid lobe. (b) After ILP, longitudinal US image shows $2.2 \mathrm{~cm} \times 1.6 \mathrm{~cm} \times 3.17 \mathrm{~cm}$ isoechoic nodule with central cystic portion in left thyroid lobe.

$\mathrm{mm}(2 \mathrm{~W}, 120 \mathrm{~s}), 9.9 \mathrm{~mm} \pm 2.5 \mathrm{~mm}(2 \mathrm{~W}, 180 \mathrm{~s}), 6.2 \mathrm{~mm} \pm 1.8 \mathrm{~mm}(3$ $\mathrm{W}, 60 \mathrm{~s}), 7.7 \mathrm{~mm} \pm 1.2 \mathrm{~mm}(3 \mathrm{~W}, 120 \mathrm{~s}), 8.8 \mathrm{~mm} \pm 0.7 \mathrm{~mm}(3 \mathrm{~W}, 180$ $\mathrm{s})$ respectively (Figures $3 \mathrm{a}$ and $3 \mathrm{~b}$ ).

We compared the volumes of the ablation lesions (Figure 4) shows the histogram of ablation lesion volume in different laser energies and irradiation time. After $2 \mathrm{~W}$ laser application for 60 seconds, the volume was $0.076 \mathrm{ml} \pm 0.006 \mathrm{ml}$ and it increased with the time of laser irradiation. The volumes were measured as $0.208 \mathrm{ml} \pm 0.034 \mathrm{ml}$ and $0.342 \mathrm{ml} \pm 0.064 \mathrm{ml}$ after 120 seconds and 180 seconds of $2 \mathrm{~W}$ laser irradiation. However, the ablation lesion volumes were higher in the case of $3 \mathrm{~W}$ laser irradiation and were measured as $0.198 \mathrm{ml} \pm 0.076$ $\mathrm{ml}, 0.371 \mathrm{ml} \pm 0.088 \mathrm{ml}$ and $0.662 \mathrm{ml} \pm 0.091 \mathrm{ml}$ after 60 seconds, 120 seconds and 180 seconds respectively.

\section{Case results}

The initial nodule volume measured with US was $16 \mathrm{~mL}$ and this decreased the nodule volume to $11.2 \mathrm{~mL}$ after 3 months (Figures $5 \mathrm{a}$ and $5 b)$. Overall, nodule volume was reduced $30 \%$. ILP was well tolerated and there was no complication. Pressure symptom was slightly reduced after 3 months.

\section{Discussion}

Although surgery has already been established as the best treatment modality for the benign and malignant thyroid lesions but surgical complications and cosmetic side effects are very common to these patients. However, selective therapeutic technology with a laser has been recognized as the ideal tool for diagnosis and treatment of thyroid nodules. ILP has the advantage of minimal invasiveness, does not involve pain and also lesser side effects. Moreover, the cost of the surgical treatment is also higher than the laser ablation. Hence it is considered for inducing a rapid cytoreduction in tumor burden prior to external radiation therapy or chemotherapy. It is also considered for local or distant recurrences of thyroid malignancy that are not amenable to surgical or radioiodine treatment. Moreover, the laser ablation techniques are very well known because of their potential accuracy in the destruction of target areas. Therefore, using optical fiber is helpful to preserve the normal tissue of the peripheral as well as smaller scars after surgery because the minimized incisions to insert. Thus, optical fibers have been used instead to incise, coagulate, and vaporize the diseased tissues [8]. These advantages of ILP over other alternative modality established ILP as a possible choice for the treatment of benign thyroid nodules in the 2010 thyroid nodule guidelines of the American Association of Clinical Endocrinologists/ Associazione Medici Endocrinologi (Italian Association of Clinical Endocrinologists)/European Thyroid Association (AACEAME-ETA) are the first to recommend percutaneous ILP [9].

In this study, we confirmed the feasibility of using $980 \mathrm{~nm}$ diode laser for interstitial laser photocoagulation before clinical application in benign thyroid nodule treatment. We irradiated the bovine liver blocks with $980 \mathrm{~nm}$ laser for the different time interval and laser energies. The liver blocks were then dissected along the axis of the laser irradiation and then transversely into slices. The inner and outer surface temperature at the zone of coagulation was measured during the laser energy delivery. The outer temperature did not change significantly during irradiation. Though the inner temperature showed an increase in temperature for higher laser power, but the changes in temperature inside the liver block was negligible for lower energy. The effects of tissue ablation were also studied by measuring the zone of coagulation necrosis. Both the longitudinal and transverse diameters were increased with time and laser energies. We compared the volumes of the ablation lesions. The ablation lesion volume was higher in the case of $3 \mathrm{~W}$ laser irradiation compared to that of $2 \mathrm{~W}$ laser energy. Therefore, laser ablation with 980 $\mathrm{nm}$ diode laser induces well-defined tissue ablation. The temperature also did not exceed the protein denaturation threshold around the zone 
Citation: Moon JH, Biswas R, You DS, Chung P (2017) Interstitial Laser Photocoagulation Using 980 nm Diode Laser in Benign Thyroid Nodule: A Feasibility Study. J Clin Case Rep 7: 1017. doi: 10.4172/2165-7920.10001017

of coagulation necrosis. Therefore, this could be a major advantage of using $980 \mathrm{~nm}$ laser for ILP.

The rate of thermal generation in the tissue is proportional to the water absorption coefficient and the fluence. A laser diode of $980 \mathrm{~nm}$ wavelength has a higher coefficient of water absorption as compared to the most commonly used of the $1064 \mathrm{~nm}$ wavelength of the Nd:YAG laser. Therefore, the $980-\mathrm{nm}$ diode laser is able to generate localized heating rapidly and the same extent of ablation zones can be created using relatively low output power [7]. We present case was tolerable treatment for benign thyroid nodule with low energy $(270 \mathrm{~J})$ and short time (90 s) compared to other pervious study $[6,10]$. Moreover, $\mathrm{Nd}$ : YAG requires higher currents and therefore higher power supplies (220 volts) as well as active water cooling for the laser, resulting in fewer areas that the laser can be operated. Diode-based lasers, on the other hand, use a semiconductor as the active medium. This reduces dramatically the power and cooling requirements allowing the lasers to be operated with lower voltage supply with air cooling only. Another advantage of using newer infrared diode-based systems operating in the range of $805 \mathrm{~nm}$ to $980 \mathrm{~nm}$ is that they utilize smaller applicators, and create larger ablation zones in shorter periods of time. Therefore, ILP with $980 \mathrm{~nm}$ diode laser could be an efficient therapeutic tool for the treatment of benign thyroid nodules.

\section{Conclusion}

ILP with $980 \mathrm{~nm}$ diode laser induces well-defined tissue ablation correlated with energy parameters in bovine liver tissue. ILP with 980 $\mathrm{nm}$ diode laser could be a therapeutic tool in benign thyroid nodular disease. It proves itself as the safe, easy-to-use tool for the thyroid treatment with minimal side effects.

\section{Acknowledgement}

This research was supported by a grant from the Korea Health Technology R\&D Project through the Korea Health Industry Development Institute (KHIDI) funded by the Ministry of Health \& Welfare, Republic of Korea (grant number: HI14C1234).

\section{References}

1. Hegedus L (2004) Clinical practice: The thyroid nodule. N Engl J Med 351: 1764-1771.

2. Mazzaferri EL (1993) Management of a solitary thyroid nodule. N Engl J Med 328: 553-559.

3. Hegedus L, Steen J, Bonnema F, Bennedbæk N (2003) Management of simple nodular goiter: Current status and future perspectives. Endocr Rev 24: 102-132.

4. Helle D, Finn NB, Laszlo H (2013) Interstitial laser photocoagulation (ILP) of benign cystic thyroid nodules--a prospective randomized trial. J Clinical Endocrinol Meta 98: E1213-1217.

5. Dossing H, Finn NB, Steen K, Laszlo H (2002) Benign solitary solid cold thyroid nodules: US-guided interstitial laser photocoagulation--initial experience. Radiology 225: 53-57.

6. Claudio MP, Giancarlo B, Stefano S, Antonio B, Rinaldo G, et al. (2004) Thyroid tissue: US-guided percutaneous laser thermal ablation. Radiology 232: 272-80.

7. Ahrar K, Gowda A, Javadi S, Borne A, Fox M (2010) Preclinical assessment of a $980-\mathrm{nm}$ diode laser ablation system in a large animal tumor model. J Vascular Interven Radiol 21: 555-561.

8. Nguyen TH, Rhee YH, Ahn JC, Kang HW (2015) Circumferential irradiation fo interstitial coagulation of urethral stricture. Optics Express 23: 20829-208240.

9. Gharib H, Papini E, Paschke R, Duick D, Valcavi R, et al. (2010) American Association of Clinical Endocrinologists, Associazione Medici Endocrinologi, and European thyroid association medical guidelines for Clinical Practice for the diagnosis and management of thyroid nodules. Endocr Pract 16 Suppl 1: 1-43.

10. Dossing H, Finn N, Laszlo H (2006) Effect of ultrasound-guided interstitial lase photocoagulation on benign solitary solid cold thyroid nodules: one versus three treatments. Thyroid 16: 763-768. 